Helmut König (Hrsg.)

Der Fall Schwerte im Kontext 
Helmut König (Hrsg.)

\section{Der Fall Schwerte im Kontext}


Alle Rechte vorbehalten

(c) Westdeutscher Verlag GmbH, Opladen/Wiesbaden, 1998

Der Westdeutsche Verlag ist ein Unternehmen der Bertelsmann Fachinformation GmbH.

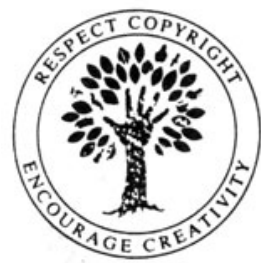

Das Werk einschließlich aller seiner Teile ist urheberrechtlich geschützt. Jede Verwertung außerhalb der engen Grenzen des Urheberrechtsgesetzes ist ohne Zustimmung des Verlags unzulässig und strafbar. Das gilt insbesondere für Vervielfältigungen, Übersetzungen, Mikroverfilmungen und die Einspeicherung und Verarbeitung in elektronischen Systemen.

http://www.westdeutschervlg.de

Höchste inhaltliche und technische Qualität unserer Produkte ist unser Ziel. Bei der Produktion und Verbreitung unserer Bücher wollen wir die Umwelt schonen: Dieses Buch ist auf säurefreiem und chlorfrei gebleichtem Papier gedruckt. Die Einschweißfolie besteht aus Polyäthylen und damit aus organischen Grundstoffen, die weder bei der Herstellung noch bei der Verbrennung Schadstoffe freisetzen.

Umschlaggestaltung: Horst Dieter Bürkle, Darmstadt

ISBN-13: 978-3-531-13146-7 e-ISBN-13: 978-3-322-83298-6

DOI: $10.1007 / 978-3-322-83298-6$ 


\section{Inhalt}

Einleitung des Herausgebers

Der Fall Schwerte und die Reaktionen

Bernd-A. Rusinek

Schwerte/Schneider: Die Karriere

eines Spagatakteurs 1936 - 1995

Albrecht Betz

Der ${ }_{n}$ Schwertträger" als Publizist.

Zu Hans Emst Schneiders Veröffentlichungen vor 1945

Walter Müller-Seidel

Probleme der literarischen Moderne.

Am Beispiel des Germanisten Hans Schwerte

Helmut König

Von der Diktatur zur Demokratie.

Der Fall Schwerte im Kontext der Bundesrepublik

Gerwin Klinger

Amold Gehlen - Theoretiker der

Führung und Mitläufer

Michael Kohlstruck

Der Fall Mehnert

Die Autoren 